Mots. Les langages du politique

\title{
Zoé Carle, Poétique du slogan révolutionnaire
}

Paris, Presses Sorbonne Nouvelle, 2019, 321 p.

\section{Dominique DESMARCHELIER}

\section{CpenEdition}

\section{Journals}

Édition électronique

URL : https://journals.openedition.org/mots/27542

DOI : $10.4000 /$ mots. 27542

ISSN : 1960-6001

Éditeur

ENS Éditions

\section{Édition imprimée}

Date de publication : 19 novembre 2020

Pagination : 168-171

ISBN : 979-10-362-0280-3

ISSN : 0243-6450

\section{Référence électronique}

Dominique DESMARCHELIER, «Zoé Carle, Poétique du slogan révolutionnaire », Mots. Les langages du politique [En ligne], 124 | 2020, mis en ligne le 01 janvier 2021, consulté le 04 janvier 2023. URL : http:// journals.openedition.org/mots/27542 ; DOI : https://doi.org/10.4000/mots.27542

Ce document a été généré automatiquement le 4 janvier 2023.

Tous droits réservés 


\section{Zoé Carle, Poétique du slogan révolutionnaire}

Paris, Presses Sorbonne Nouvelle, 2019, 321 p.

Dominique DESMARCHELIER

\section{RÉFÉRENCE}

Zoé Carle, Poétique du slogan révolutionnaire. Paris, Presses Sorbonne Nouvelle, 2019, $321 \mathrm{p}$.

1 L'ouvrage de Zoé Carle, issu d'une thèse soutenue en 2017, a pour ambition d'étudier, dans un même mouvement, « les caractéristiques formelles et matérielles, les modalités d'élaboration et les vies sociales des slogans ».

2 Les six chapitres, organisés en trois parties, se proposent d'analyser des corpus riches et variés : des cris de la foule lors de la Commune de Paris en 1871 aux manifestations qui se sont déroulées au Caire entre 2011 et 2014, sans oublier les slogans de Mai 68 en France ou encore la littérature prolétarienne à travers un roman italien.

3 La première partie est consacrée aux scènes, aussi bien révolutionnaires que littéraires. Les deux chapitres qui la composent permettent à l'auteure de présenter en détail ses corpus, notamment les slogans qu'elle a recueillis en Égypte lors des manifestations. Une attention particulière est portée sur le rythme de profération, en liaison avec la marche des cortèges. On pense évidemment aux travaux précurseurs du sociolinguiste Louis-Jean Calvet (1976), cité dans la bibliographie de l'ouvrage.

4 La deuxième partie, qui reprend le titre de l'ouvrage, s'attache à mettre en évidence la poétique des slogans, au sens où l'entend Roman Jakobson, c'est-à-dire non seulement leur mode de création (voir l'étymologie grecque du mot), mais aussi leur mode de réception, et le degré de poéticité qu'on peut y déceler. L'auteure rappelle que le " terme slogan apparaît en français en 1842 avec le premier sens de "cri de guerre d'un clan" "(p.101). Tombé en désuétude à la fin du XIX siècle, il réapparaît dans les années 1930, dans les domaines de la publicité et de la politique. Véhiculant une 
connotation négative, liée à l'idée de propagande, il prend, lors des manifestations, une dimension performative. Le parti pris de traiter ensemble slogans oraux et slogans écrits, parfois accompagnés d'images, s'inscrit dans une perspective sémiotique.

5 Par ailleurs, Zoé Carle ne manque pas, tout en les distinguant des slogans révolutionnaires, de rappeler les nombreux travaux consacrés aux «slogans publicitaires ", en particulier ceux de Jean-Michel Adam et Marc Bonhomme (Adam, Bonhomme, 1997).

6 L'auteure décrit avec précision la diversité des formes, s'attachant aux «slogans proférés » lors des manifestations, sous des formes brèves. Citant André Gide, qui, dans son journal, emploie le mot formule à propos des slogans publicitaires, Zoé Carle revient sur la définition de ce terme, amplement décrit dans les travaux d'Alice Krieg-Planque, curieusement oubliés dans la bibliographie (Krieg-Planque, 2009 ; Krieg-Planque, Oger, 2018).

7 Devant la difficulté à établir une définition formelle du slogan, c'est à Jean-Claude Anscombre $(1994,2000)$ que l'auteure fait appel, pour ne pas limiter l'étude à un cadre strictement grammatical. Rejoignant en cela les remarques de L.-J.Calvet, J.C. Anscombre insiste, à propos des proverbes, sur les procédés paratactiques, le recours aux onomatopées ou aux réduplications de syllabes. Cette " compétence rythmique " semble alors au cœur de la réussite, ou non, d'un slogan. L'appropriation d'un slogan John Austin parlerait de " condition de félicité ou de réussite »- dépendra tout à la fois $\mathrm{du}$ contexte d'énonciation, du statut des énonciateurs et des énonciataires, et du cadre dans lequel l'échange se déroule.

8 À ces analyses de slogans proférés à valeur performative, Zoé Carle tient à ajouter celle de leur dimension graphique, en se référant aux travaux de Béatrice Fraenkel sur les « actes d'écritures» $(2006,2008,2011)$. La poétique du slogan conduit à s'interroger sur son caractère plus ou moins éphémère. C'est le linguiste Charles Bally qui est cette fois convoqué pour insister sur le refus de distinguer entre usage littéraire et usage normal de la langue. Pour ce dernier, « la créativité s'étend très au-delà du seul art littéraire » (Bally, 1932, p. 164).

9 La troisième partie de l'ouvrage aborde la dimension polémique du slogan. Pour Gilles Declercq, le slogan, comme forme inquiétante de la rhétorique, par son caractère violent, apparaît comme un "espace féroce de la conquête et de la prédation " (Declercq et al. éd., 2003, p. 17). Privilégiant une vision esthétique de la réception, Ross Chambers considère que les "poèmes étaient comme certains graffitis " (cité dans Adam, 1992, p. 62). La remarque s'applique à l'espace urbain (réclames, affiches), qui est perçu comme « sur-sémiotisé ».

10 Dans le cinquième chapitre, Zoé Carle reprend les trois lieux classiques de la rhétorique. Elle définit un ethos du «nous » qui s'opposera à un « eux » et un « vous ». Sa connaissance de la langue arabe (dans sa variété égyptienne) lui permet d'insister de façon fort pertinente sur la différence entre l'usage d'un «nous » dialectal et d'un «nous » classique.

11 Le rôle du pathos, favorisant le recours aux émotions, conduit à se méfier de tout slogan révolutionnaire. On peut alors s'interroger sur le ou les destinataires du slogan.

12 Quant au logos, le texte réfute l'idée que le slogan serait une forme " peu argumentée » (Genette, 1982, p. 188) et lui oppose la vision défendue par Christian Plantin, pour qui 
l'on serait en présence d'« énoncés fermés à tout véritable enchaînement argumentatif et à toute interaction » (Plantin, 1990, p. 152).

Le dernier chapitre aborde la dimension patrimoniale du slogan. Comment une œuvre d'art se métamorphose-t-elle en bien marchand? On a tous en mémoire la reprise des affiches de Mai 68 par de grandes enseignes commerciales (Montety, 2012). Zoé Carle analyse également le devenir d'un slogan initié en 1977 par une organisation militante italienne, complété par une vieille photo datant de 1905 :

«Sarà una risata che vi seppellirà »: Ce sera un éclat de rire qui vous enterrera.

"Sarà un risotto che vi seppellirà »: Ce sera un risotto qui vous enterrera.

«Sarà une selfie che vi seppellirà »: Ce sera un selfie qui vous enterrera.

Pour conclure, en insistant sur la richesse des corpus proposés par Zoé Carle, on soulignera l'originalité de la démarche, qui combine analyse de discours oraux et écrits, remarques rythmiques et description poétique.

\section{BIBLIOGRAPHIE}

ADAM Jean-Michel, 1992, Pour lire le poème, Bruxelles, De Boeck.

ADAM Jean-Michel, BONHOMME Marc, 1997, L'argumentation publicitaire : rhétorique de l'éloge et de la persuasion, Paris, Nathan.

ANSCOMBRE Jean-Claude éd., 2000, La parole proverbiale [numéro thématique], Langages, n 139.

ANSCOMBRE Jean-Claude éd., 1994, « Proverbes et formes proverbiales : valeur évidentielle et argumentative », Langue française, $n^{\circ}$ 102, p. 95-107.

BALLY Charles, 1932, Linguistique générale et linguistique française, Paris, Ernest Leroux.

CALVET Louis-Jean, 1976, La production révolutionnaire : slogans, affiches, chansons, Paris, Payot. DECLERCQ Gilles, MURAT Michel, DANGEL Jacqueline éd., 2003, La parole polémique, Paris, Honoré Champion.

FRAENKEL Béatrice, 2011, " “Nos drapeaux sont des foulards à fleurs” : les manifestations du MLF ", dans C. App, A.-M. Faure-Fraisse, B. Fraenkel et al., 40 ans de slogans féministes : 1970-2010, Donnemarie-Dontilly, Éditions iXe, p. 5-17.

FRAENKEL Béatrice, 2011, 2008, « Les affiches en Mai 68 : l'atelier populaire des Beaux-Arts », dans P. Artières et M. Zancarini-Fournel éd., 68, une histoire collective (1962-1981), Paris, La Découverte, p. 276-281.

FRAENKEL Béatrice, 2011, 2006, « Actes écrits, actes oraux : la performativité à l'épreuve de l'écriture ", Études de communication, n² 29, p. 69-93.

GENETTE Gérard, 1982, Palimpsestes : la littérature au second degré, Paris, Seuil.

KRIEG-PLANQUE Alice, 2009, La notion de "formule » en analyse du discours : cadre théorique et méthodologique, Besançon, Presses universitaires de Franche-Comté. 
KRIEG-PLANQUE Alice, OGER Claire, 2018, « Slogan », dans Publictionnaire : dictionnaire encyclopédique et critique des publics, Metz, CREM, Université de Lorraine, http://publictionnaire.huma-num.fr/ notice/slogan/ (consulté le 13 juillet 2020).

MONTETY Caroline de, 2012, « À vos caddies, citoyens ! La révolution, motif politique saisi par la publicité », Mots. Les langages du politique, $\mathrm{n}^{\circ} 98$, p. 63-78.

PLANTIN Christian, 1990, Essais sur l'argumentation : introduction à l'étude linguistique de la parole argumentative, Paris, Kimé.

\section{AUTEURS}

\section{DOMINIQUE DESMARCHELIER}

Linguiste 